\title{
Juana Manuela \\ Gorriti, una \\ periodista argentina \\ del siglo XIX
}

Marina Liliana Guidotti

Marina Liliana Guidotti es

doctora en Letras, Universidad

del Salvador, Buenos

Aires, Argentina. Contacto:

marinaguidotti@gmail.com 
palabras-clave

Argentina, siglo XIX, periodis-

mo, mujeres, Gorriti. resumen

Juana Manuela Gorriti, (Argentina, 1816-1892), demostró poseer un especial talento como escritora de narrativa pero también una gran ductilidad, capacidad y perspicacia para dar cuenta de acontecimientos históricos, eventos culturales, pensamientos y sensibilidad de las sociedades de las que formó parte. En el ámbito periodístico alcanzó notable reconocimiento al colaborar asiduamente en importantes periódicos de toda América. Su proyecto más ambicioso en este campo fue el lanzamiento, en Buenos Aires en 1877, de La Alborada del Plata, que dirigió hasta 1878 , en que otras escritoras continuaron su legado. Del análisis de los artículos editoriales que en el presente trabajo se estudian, se desprende que son de su autoría, tanto por las marcas de la enunciación en el discurso como por las ideas allí desarrolladas, ya que coinciden con las opiniones que expuso y defendió en toda su producción: una visión americanista que contemplaba la conservación de las lenguas regionales y los rasgos particulares de cada nación; una permanente y activa defensa de la educación femenina; una preocupación por incorporar los beneficios de las ciencias a la vida cotidiana y una actitud comprometida con la consolidación de un sistema democrático de gobierno en el que las mujeres tuvieran activa participación. 
keywords

Argentina, nineteenth century, journalism, women, Gorriti. abstract

Juana Manuela Gorriti (Argentina, 1816-1892) has shown a special talent as a writer, as well as a great capacity and perspicacity to provide an insightful view of the historical and cultural events that she participated in, and to describe the ways of thinking and feelings of the societies she belonged to. In the journalistic arena, she reached notable recognition by working assiduously in important journals across Latin America. Her most ambitious project in this field was the creation of $\mathrm{La}$ Alborada del Plata. Gorriti directed this journal from its launch in Buenos Aires in 1877 up to 1878 , when other female writers continued her legacy. Our current analysis of the editorial articles published in this journal demonstrates that they were penned by Gorriti, based on specific textual indications and in the ideas presented, which coincide with her long-held opinions and values that she defended throughout her career. In particular, Gorriti proposed an americanist vision of conservation of regional languages and the identifying traits of each Nation; a permanent and active defense of female education; a strive to incorporate the benefits science's improvements to everyday life, and a compromise to consolidate a democratic government system in which women could more actively participate 
EL PERIODISMO REFLEjA LA HISTORIA viva de una sociedad, es el eco de los hechos, la cultura, el pensamiento y el arte que en ella se desarrollan. Si bien el rol de la mujer americana del siglo XIX en esta tarea no estuvo asociado al éxito comercial, los escritos periodísticos de Juana Manuela Gorriti ${ }^{\mathrm{I}}$ (Sosa de Newton I986, 286-287) ocuparon un lugar destacado dentro de su extensa producción literaria. Fundó y dirigió la publicación periódica La Alborada del Plata ${ }^{2}$ y con particular sensibilidad volcó sus ideas sobre las prácticas culturales, sociales y políticas de su tiempo.

A la par de otras actividades como la tarea educativa, la organización de reuniones literarias y la realización de una cuantiosa y trascendente obra narrativa, desplegó una muy importante labor periodística que también debe ser rescatada y comentada, ya que sus contribuciones se encuentran en publicaciones de Argentina, de Perú y de otros países de América. Escribió para diarios y revistas como El Comercio de Lima, El Liberal de Lima, El Álbum, El iris, La Revista del Paraná, La Revista de Buenos Aires, La Revista del Río de la Plata, El Álbum del hogar y La Ondina del Plata.

En I877, al encontrarse en Buenos Aires, tomó la decisión de fundar un periódico como el que en 1874 había creado en Lima conjuntamente con el poeta Numa Pompilio Llona 3 bajo el nombre de La Alborada de Lima ${ }^{4}$. Consideró

I Juana M. Gorriti, nació en Salta en I816 y falleció en Buenos Aires en I892. Sus Obras Completas fueron publicadas por la Fundación del Banco del Noroeste, Salta, I982, VI tomos, como homenaje en el centenario de su muerte y con la intención de rescatar, de esa manera, parte del patrimonio cultural argentino. Las referencias textuales se realizarán sobre la base de esta edición.

2 La Alborada del Plata comenzó a editarse en Buenos Aires el i8 de noviembre de I877. Constaba de 8 páginas por número y no incluía publicidad. La casa editora era la Imprenta Biedma, ubicada en la calle Belgrano I35. Las transcripciones incluidas en el presente trabajo son copia fiel de la publicación que se encuentra en la Sala del Tesoro de la Biblioteca Nacional de Buenos Aires.

3 Numo Pompilio Llona, Guayaquil (I832-I907).

4 Citado por Mary G. Berg, I997, I3I-I46. 
que ese título reflejaba sus ideas y las de muchos otros escritores que veían la necesidad de contar con un órgano de difusión del pensamiento americano. Así como aquella publicación limeña aludía a un despertar, a un nacimiento, de la misma manera esperaba que este emprendimiento porteño fuera el vehículo que canalizara las inquietudes que percibía en la Buenos Aires de ese momento. La ciudad-puerto, a partir de I865, había comenzado a vivir una época de esplendor y prosperidad económica que pudo afianzarse debido a la consolidación de la paz social y política. Sin embargo, ya más próximo a los 80 , el ambiente había cambiado: ahora los problemas políticos del país absorbían el interés de los ciudadanos; las guerras contra los indios ya habían finalizado y, como consecuencia, pudieron incorporarse vastas extensiones de tierras productivas; se imponía el liberalismo positivista y los intelectuales participaban en la política, en la vida militar, a la par que incursionaban en la literatura y el periodismo.

Las mujeres no fueron ajenas a estos cambios; varias escritoras argentinas Juana Manuela Gorriti, Eduarda Mansilla, Rosa Guerra, Juana Manso, Josefina Pelliza, Lola Larrosa, entre otras - y americanas - Clorinda Matto, Mercedes Cabello, Manuela Villarán, Rosa M. Riglos, Mercedes Belzú, por sólo mencionar algunas -, dejaron su impronta en el periodismo y ocuparon un espacio que no siempre fue reconocido en el canon literario de sus países natales.

A través de esta actividad, Juana Manuela Gorriti reflejó los temas que siempre le interesaron: el papel de la mujer en la sociedad, la educación, la ciencia y la política (Lojo, I997, I92-I97). Cada uno de ellos fue vivenciado desde su infancia, y estas experiencias quedaron plasmadas en sus escritos. En ellos se demuestra un espíritu combativo que luchó por defender no sólo su identidad y sus orígenes sino que asumió la voz silenciada de muchas mujeres que, acercándose ya el final del siglo XIX, no tenían posibilidad de acceder a la instrucción ni conocían sus derechos. 
Al abordar este aspecto de su obra, y en particular las notas editoriales de su periódico, nos proponemos desentrañar su ideología, analizar las características de su discurso, ver de qué manera influyó en la construcción de una identidad lingüística y cultural, no sólo argentina sino americana, y entender cómo las circunstancias que rodearon su vida fructificaron en el alma y la mente de esta mujer excepcional que tuvo la capacidad y la entereza de aprehender una realidad tan rica y a la vez conflictiva, y volcarla en artículos pensados para ser publicados en la prensa argentina.

los gorriti, la genealogía

La vida y obra de esta escritora estuvieron signadas por los problemas políticos que se vivían en la Argentina decimonónica (Berg, I994, 69-70). Como les ocurrió a tantas otras familias, las luchas posteriores a la Independencia determinaron la suerte de su padre, José Ignacio Gorriti, dos veces gobernador de la provincia de Salta - de ideas unitarias, que debió optar por el exilio -, así como la de sus tíos Juan Ignacio, el canónigo, y Francisco José, “el Pachi”, el único que seguía los lineamientos federales. Eso desembocó en que en el seno familiar se vivieran las mismas desavenencias internas que asolaban al país: fue inevitable el enfrentamiento entre unitarios y federales. Estos antecedentes influyeron en la futura escritora, quien demostró sostener una mirada atenta sobre los conflictos políticos que viviría no sólo en Argentina sino también en Bolivia y en Perú, países igualmente convulsionados y en los que transcurrió gran parte de su vida.

En diferentes producciones literarias reflejó ese contexto histórico (Batticuore, 2005, 29I-293), generalmente, a través de amores trágicos entre parejas de banderías opuestas, tema eje de cuentos como "El guante negro", "La hija del masorquero", "La novia del muerto", "El lucero del manantial” y "Una noche de agonía", todos ellos incluidos en Sueños y realidades, publicado en I865, 
el mismo año en que murió su esposo, Manuel Isidoro Belzú, quien había llegado a ocupar la más alta dignidad como funcionario de su país: fue presidente de Bolivia entre 1850 y 1855 .

A Juana Manuela el mundo de la cultura no le fue ajeno, debido a la formación intelectual con que contaba la familia Gorriti (Efrón, I998, 9-58). Juan Ignacio, además de su formación eclesiástica, había cursado estudios de Letras. A esa potencial influencia literaria se sumó la posibilidad de acceder a la importante biblioteca que su padre había reunido en la hacienda Los Horcones, adquirida por su abuelo paterno -proveniente de la provincia de Guipúzcoa luego de radicarse en Salta en I758. Esa biblioteca, que reunía material no sólo literario sino jurídico, filosófico y teológico, debe de haber roto las compuertas de la imaginación de una lectora tan ávida como era Juana Manuela. No hay que olvidar que, a lo largo del siglo XIX, la lectura educó la sensibilidad femenina y fue considerada valiosa socialmente (Catelli, 200I, 2I-25).

En I83 la familia Gorriti debió emprender el exilio hacia Bolivia. Dos años después la joven salteña se casó con el general Belzú. Luego de acompañar a su esposo en diferentes destinos, el matrimonio debió trasladarse a Sucre en I835, lo que le permitió reencontrarse con su familia (Deleis, 200I, I4I-I55). Allí tuvo la oportunidad de participar en las veladas literarias organizadas por su tío materno, Facundo Zuviría5, quien en ese momento era el editor de tres periódicos: La Gaceta, El Restaurador y La Columna; quizás él le enseñara los rudimentos del oficio.

Pero es indudable que sólo un espíritu abierto como el suyo fuese capaz de convertirse en receptor y difusor de los pensamientos, las novedades científicas y literarias que llegaban a América. Lo demostró tanto en el espacio de la

5 Facundo Zuviría, (I796-I86I). Una Selección de escritos y discursos se encuentra microfilmada en la UNC de Chapel Hill, EE.UU. 
escritura como en el de la organización de los Salones Literarios que iba creando en cada uno de los lugares donde establecía su residencia. Así surgieron esos espacios de reflexión, creación y discusión: en Oruro dio acogida a "Los Caballeros de la Espuela Dorada"; en la Paz, los organizó en I835 y en I839; en Lima los creó a fines de la década del cuarenta y allí formó parte - junto con Ricardo Palma y José Antonio de Lavalle, entre otros -, de la generación conocida como la Bohemia Literaria. Nuevamente en Lima, en I876, inauguró las Veladas Literarias, con la particularidad de que en ellas participaron conocidas escritoras como Mercedes Cabello, Clorinda Matto y Carolina Freyre ${ }^{6}$. Al siguiente año debió establecerse temporariamente en Buenos Aires y a pesar de su corta permanencia en la ciudad, tuvo oportunidad de abrir también su casa para realizar sus ya famosas reuniones literarias.

Ejemplo tangible de la labor que desplegó en Perú es la recopilación que efectuó en I892 de esas actividades bajo el título de Veladas literarias en Lima7. Estos textos la descubren como el epicentro de las reuniones y figura aglutinante en torno a la cual fue posible propagar la cultura así como los cambios económicos y políticos ocurridos en el mundo y especialmente en América (Batticuore, 1999, 39-50).

Otro ámbito, el educativo, no sólo le fue conocido sino que por medio de él logró sostener su nuevo hogar en Lima, al que llegó con sus dos hijas luego de tomar, en I847, la decisión irrevocable de separarse de Belzú. Allí comenzó

6 Todas ellas de reconocida trayectoria en el ambiente intelectual de Lima. Además de cultivar la poesía, el cuento y la novela, participaban en la redacción de textos escolares, en la publicación de artículos para distintos periódicos así como en las tertulias y veladas literarias, en donde a la par de los hombres trataban temas culturales y políticos. Clorinda M. de Turner tuvo que exiliarse a Buenos Aires donde colaboró en las publicaciones que ya existían en ese momento y en I895 dirigió el Búcaro Americano, periódico de las familias, de larga trayectoria en nuestro país pues se continuó editando hasta I9०9.

7 Juana M. Gorriti, Veladas literarias de Lima, 1876-1877; tomo primero, veladas I a X. Buenos Aires: Imprenta Europea, I892. 
a dictar clases a niñas de las familias más importantes de la ciudad, e inauguró una escuela de primeras letras. No hay que olvidar que su padre, siendo gobernador, había llevado a la práctica importantes reformas en ese campo: propició la instrucción pública, incorporó el sistema educativo lancasteriano ${ }^{8}$, por el cual los alumnos más aventajados se convertían en 'maestros' de quienes recién comenzaban su aprendizaje, y fundó una escuela de monjas.

El interés por la docencia continuó durante toda su vida y seguramente esa inquietud la llevaría años más tarde a entablar una amistad con otra Juana, educadora, escritora, interlocutora de Sarmiento y fundadora del periódico literario Álbum de Señoritas: Juana Manso99.

Desde joven, Juana Manuela evidenció una personalidad signada por un fuerte individualismo tanto en sus pensamientos y opiniones como en sus decisiones, pero también demostró poseer una gran capacidad para escuchar, para observar el entorno que la rodeaba y aquilatarlo en lo íntimo de sus recuerdos. Todas estas experiencias de vida serán las fuentes de las que se nutrirá no sólo para elaborar sus producciones literarias sino también para la redacción de sus artículos periodísticos.

Su prodigiosa memoria le permitió evocar acontecimientos históricos, relatos, leyendas, tanto de amigos de la familia como de personas que estuvieron sirviendo en la casa paterna. Todos esos recuerdos cobrarán forma en sus narraciones y se volcarán en dos corrientes: una popular y otra histórica. De la

8 Quien introdujo el sistema lancasteriano en la Argentina fue Diego Thompson en I8I8.

9 Juana P. Manso de Noronha (I8I9-I875). Escritora, educadora y periodista. Por razones políticas vivió en Montevideo donde estuvo al frente de una institución educativa. Posteriormente se trasladó a Río de Janeiro; allí se casó con un violinista al que acompañó en giras por Estados Unidos y La Habana para luego volver a Brasil. Regresó a Buenos Aires en I853, destacándose como escritora y periodista, actividad que le permitió convertirse en la editora de la revista Álbum de señoritas en I854 y, posteriormente, de La Siempre-viva, en I864. Desarrolló, asimismo, una importante tarea educativa de acuerdo con las pautas que en la materia trazara Domingo Faustino Sarmiento. 
primera, podemos tomar como referencia el relato "Gubi Amaya, historia de un salteador", incluido en Sueños y realidades (I865), que le fue relatado en su infancia por un hombre de campo que servía en la hacienda de su padre. Por otro lado, su versión de la Historia quedó plasmada en distintas obras: Vida militar Y política del General Don Dionisio Puch10 ${ }^{\mathrm{IO}}$ (I868), en la que incluye una semblanza de Martín Miguel de Güemes ${ }^{\text {II }}$ y recrea su actuación militar; Panoramas de la vida (1876), que contiene relatos provenientes de ambas vertientes: de la primera, se destaca El pozo del Yocci, y de la segunda, Belzú ${ }^{12}$. También se convirtió en cronista de las terribles batallas que enfrentaron los peruanos ante la llegada de la Armada española; esos episodios fueron recogidos posteriormente en Misceláneas, (1878).

Las vivencias de su niñez y juventud le permitieron recrear y crear la historia de su provincia y la de la nación, retratar a los hombres y a las

Dionisio Puch fue concuñado de Juana Manuela, hombre a quien ella admiró desde muy joven. Al describir la vida del militar, lo hace con su particular visión y a través de ella realiza la lectura de los hechos que éste protagonizó.

II Líder de la guerra gaucha en defensa de la Argentina contra los españoles, (I785-I82I). Fue militar de carrera, participó en la defensa de la ciudad de Buenos Aires durante las invasiones inglesas, colaboró posteriormente en el sitio de Montevideo. Regresó a su Salta natal y en I8I5 fue electo gobernador de su provincia. San Martín y Pueyrredón alabaron sus dotes militares y le confiaron la defensa de la frontera norte del país. Supo enfrentar los distintos ataques realistas que minaban la seguridad de la provincia en ocho oportunidades; murió a causa de un disparo en la espalda pero no sin antes dar las órdenes para la defensa, del que sería el último ataque español y del que los salteños salieron victoriosos.

Después de la muerte de su esposo, Juana Manuela redacta esta biografía en la que lo muestra como un hombre ilustre que desarrolló una brillante carrera militar. Él fue quien organizó las revueltas contra dos presidentes bolivianos - Ballivián y Velasco - por ejercer el poder de manera despótica. Manuel Isidoro Belzú, nacido en La Paz en I808, fue el décimo presidente constitucional de Bolivia entre I850 y I855. Posteriormente viajó a Francia como Ministro y regresó en I864. Organizó entonces una revolución contra Mariano Melgarejo, el dictatorial presidente, quien lo asesinó en el palacio de Gobierno de La Paz en I865. La escritora, a partir de su propia mirada, rescata al hombre público, mientras que la mujer deja de lado su corazón y olvida las desavenencias de la vida conyugal. 
JUANA MANUELA GORRITI, UNA PERIODISTA ARGENTINA DEL SIGLO XIX

MARINA LILIANA GUIDOTTI

mujeres que ayudaron a forjarla o que lucharon por mantenerla independiente a pesar de la sangre que debió derramarse hasta la consolidación definitiva de la Patria.

JUANA MANUELA GORRITI, DIRECTORA DE LA ALBORADA DEL PLATA

El emprendimiento periodístico que llevó a cabo al publicar La Alborada del Plata debe valorarse no tanto por la cantidad de números editados bajo su dirección sino por el hecho de tomar la decisión y la responsabilidad de presentar al público un periódico dedicado a Literatura, Artes, Ciencias, Teatros y Modas.

Esse semanario, que tuvo distintas conducciones e incluso sufrió modificaciones en su título, siempre fue dirigido por una mujer. Apareció en forma discontinua en dos etapas: la primera correspondió a los años I877-I878 y la segunda, a comienzos del año I88o. De este corpus, los primeros nueve números fueron responsabilidad directa de Juana Manuela Gorriti, quien editó esta publicación dominical entre el I 8 de noviembre de I877 y el I3 de enero del siguiente año. En ese número la directora aclara que, por alejarse del país, delega la responsabilidad de sus funciones en una de sus colaboradoras, Josefina Pelliza de Sagasta ${ }^{13}$, que continuará al frente de la revista ${ }^{\mathrm{T}}$ durante las siguientes diez entregas. Desde el inicio del número quince, $\mathrm{I}^{\circ}$ de marzo de

Esta escritora de Entre Ríos nacida en I848 tuvo una destacada actuación en el ámbito intelectual debido a la importante producción poética y narrativa que desarrollara en Buenos Aires, donde residía y había conformado su hogar. Desgraciadamente Josefina P. de Sagasta falleció a los cuarenta años, en I888.

I4 Tanto Francine Masiello como Néstor Auza se refieren a esta publicación indistintamente como "periódico, publicación periódica o revista". Tal vez por su carácter literario la incluyan en esta última categoría. Distinta es la situación de la Ondina del Plata, cuyo subtítulo reza: Revista semanal de Literatura y Modas. Director Luis Telmo Pintos, Buenos Aires, I875. El Diccionario de la Real 
ı878, aparecerá en forma quincenal. Durante esa primera etapa La Alborada del Plata presentó un total de ig números y finalizó su publicación el I ${ }^{\circ}$ de mayo de 1878 .

Dos años más tarde, bajo la dirección de Juana Manuela Gorriti y Lola Larrosa de Ansaldor5, comenzó a editarse nuevamente con el mismo nombre el I ${ }^{\circ}$ de enero de 1880 consignando: $2^{\text {a }}$. Época. - Año I. - $n^{\circ}$ I., y si bien presentaba algunas modificaciones tipográficas, mantuvo la misma orientación.

La codirección comprende sólo los dos primeros números; desde el tercero, la publicación fue quincenal y estuvo a cargo de Lola Larrosa, quien implementó una modificación temática al limitar las áreas de interés a Literatura - Artes - Ciencias. También se originó un cambio en el título: a partir del $n^{\circ} 4$ fue La Alborada Literaria del Plata. En esa segunda etapa la publicación alcanzó un total de I8 números entre enero I de i880 y mayo 9 del mismo año.

Para conocer las ideas que llevaron a esas mujeres - a costa de un importante sacrificio personal - a ponerse al frente de tal emprendimiento, es necesario analizar no solamente lo que ellas dicen y corroboran con sus firmas sino también lo que puede leerse 'entre líneas', que correspondería a la organización de los artículos presentados, su contenido o los comentarios que bajo seudónimo realizaban en la sección final de cada número publicado. De esta manera se puede tener una idea más cercana a los pensamientos, intereses y proyectos de estas periodistas del último cuarto del siglo XIX.

El "Prospecto” con el que encabeza Juana Manuela Gorriti el primer número de I877 es una declaración de principios y una síntesis de las particularidades

Academia Española define 'revista' como: "publicación periódica por cuadernos con escritos sobre varias materias o sobre una sola especialmente".

I5 Lola Larrosa de Ansaldo (I859-I896). Escritora uruguaya, desarrolló toda su producción en Buenos Aires. Como novelista escribió Las obras de misericordia, ¡Hija mía!, El lujo y Los esposos; como periodista estuvo al frente de la Alborada Literaria del Plata. 
que tendrá ese semanario. Ya en el primer párrafo define el carácter de la publicación como "periódico literario" y establece una tácita comparación con otros de la misma índole pero cuya circulación quedaba sólo reducida al ámbito local, lo que significaba descuidar o no valorar las posibilidades de expansión hacia el resto de América.

La autora consideraba fundamental que las producciones fueran "amenas" para despertar así el interés de cualquier lector americano. Esta indicación conforma en sí una marca de estilo, pues presupone que los artículos debían escribirse en un nivel de lengua estándar, que pudiera ser comprendido por receptores de distintas nacionalidades; asimismo emitía un juicio de valor al criticar la postura que podría denominarse "conservacionista" de aquellos que sólo promovían a los autores conocidos o cuyos temas eran muy localistas. De allí que planteó la necesidad de que los textos publicados fueran "inéditos o poco conocidos", lo que garantizaba a los futuros lectores encontrar un material hasta entonces no publicado. Esta propuesta trasluce su intención de atraer y captar no sólo al público femenino, sino a todos aquellos que tuvieran acceso a la lectura de su publicación.

Al referirse a sus colaboradores, los destaca como "los primeros" de cada nación americana y los califica de "gallarda falange", cuyas contribuciones han de honrar las letras de todo el continente y han de tender un puente entre culturas al ser conocidas en Europa.

Es clara y concisa al enumerar las temáticas que se desarrollarán en el semanario: “ciencia, literatura y poesía de América”, pero advierte que no descuidará otros aspectos relacionados con los hechos culturales más importantes que se registren en el Viejo Continente. Por lo tanto, el propósito de la publicación será el de brindar una amplia cobertura tanto nacional como internacional, lo que pone de manifiesto la modernidad de su discurso (Masiello, I994, 7-I9).

Otra marca de su impronta es la predilección que demuestra por un género, la novela, a la que juzga la más apta para transmitir al público - función 
didáctica de la escritura -, elementos de historia y geografía que les permitirán acrecentar sus conocimientos.

Para captar el interés y la atención de los destinatarios enumera luego las secciones que podrán encontrarse en La Alborada del Plata, once en total, pero que en la práctica no llegaron a desarrollarse como tales. Así, por ejemplo, “Artes, Teatro, Crítica Literaria, Moda”, no tendrán una columna específica, pero de alguna manera son suplidas por los comentarios que la misma editora, con el seudónimo de Emma, plasma en la última sección, “Mosaico”. La elección del título del apartado es un acierto, ya que a través de distintos mosaicos va conformando ese piso que alberga no sólo a la escritora sino a todos aquellos que concurren a tertulias, bailes, representaciones teatrales, actos de beneficencia, y que constituyen en sí mismos fragmentos, episodios de la realidad social y cultural de los argentinos de fines del siglo XIX. Juana Manuela se convierte con sus palabras en la artesana que irá construyendo ese piso imaginario que puede pensarse como un damero de blancos y negros, o tal vez de guardas que enmarcan espacios lisos, propios de la época. Recrear esos salones como el lugar de reunión y alarde donde se desarrollaban las veladas literarias es pensar en filigranas verbales, colorido y gracia, visualizadas por medio de sus descripciones de acontecimientos sociales, vestimentas, costumbres, novedades literarias y romances.

Antes de finalizar el "Prospecto", insiste en un tema que se reitera como una constante: su preocupación por establecer conexiones que relacionen a las distintas naciones mediante "vínculos morales", lo que demuestra que percibe una conciencia de valores e ideales compartidos por los habitantes de los distintos países de América ${ }^{\mathrm{I} 6}$. Considera que en Europa no se han reconocido

I6 Tampoco descuida el papel de las distintas lenguas de cada región. Las valoriza y trata de hacer tomar conciencia de la necesidad de su preservación y difusión. Así lo demuestra el artículo aparecido en el $\mathrm{n}^{\circ} 2$, "Analogías filológicas de la lengua aimara", escrito por un colaborador de Bolivia. 
JUANA MANUELA GORRITI, UNA PERIODISTA ARGENTINA DEL SIGLO XIX

MARINA LILIANA GUIDOTTI

suficientemente los valores de los escritores americanos; este juicio taxativo de la editora revalida su postura americanista ${ }^{17} \mathrm{y}$ su deseo de poder lograr con La Alborada del Plata una difusión masiva que trascienda incluso las costas americanas.

juana manuela gorriti, ¿responsable de las notas editoriales?

$\mathrm{Al}$ analizar el contenido de los textos publicados bajo su dirección, en cada presentación del semanario aparece - entre los números 2 y 8 -, un primer artículo, sin firma, que corresponde por sus características a una nota editorial. El resto de las secciones o colaboraciones indican los nombres de quienes con su firma se hacen responsables de los contenidos de las mismas.

En todo texto narrativo el narrador deja sus huellas, proporciona información sobre su persona y el contexto en el que escribe (Molina, I999a, 54-72). Por medio de estas marcas - empleo de deíticos, el uso del presente u otros tiempos verbales, la interpelación al lector, el empleo de frases interrogativas y exclamativas - se puede identificar la ideología de quien escribe. Por las temáticas abordadas en los editoriales y el estilo de redacción se reconoce la pluma de Juana Manuela.

El artículo editorial del número 2, del domingo 25 de noviembre de I877, lleva por título "La ciencia" ${ }^{18}$.

I7 Se propone rescatar la historia de los habitantes americanos no sólo en La Alborada sino también en algunos de sus relatos como "La quena o la receta del cura de Yana-Rumi", publicada en el n 6 . En el semanario se editan en diferentes números colaboraciones que desarrollan esta temática, en el $n^{\circ}$ 3, la de un escritor de La Paz, "Los hijos del sol, tradición incasica"; en el n 5, "Un cataclismo en la época de los Incas", de un escritor peruano.

I8 Hay que tener en cuenta que desde mediados del siglo XVIII se había producido el triunfo del modelo cultural de las Luces, que propiciaba la investigación de la racionalidad, el estudio del funcionamiento del espíritu científico, la secularización del conocimiento, y que se veía como certeza que el desarrollo 
La voz de la editora se hace presente desde el primer párrafo, ya que luego de calificar a la ciencia como un "precioso legado", se incluye y nos incluye como receptores, en el deber de "propender por todos los medios á su adelanto y engrandecimiento". No obstante, la define como "talismán precioso”, lo que nos permite observar que relaciona la ciencia con el mundo mágico, el mundo que puede ser fuente de bienes o daños, según el uso que los hombres hagan de ella. Más adelante vuelve a aparecer la idea de lo sobrenatural, al mencionar como "instrumentos mágicos" al compás y a la regla. Son frecuentes en la prosa de Juana Manuela estas referencias a lo mágico como se comprueba, por ejemplo, en el relato El Pozo del Yocci ${ }^{\text {19. }}$

Finaliza la nota con un pensamiento en el que prevalece la convicción de que más allá de los logros de la ciencia, siempre debe existir una idea de trascendencia:

El hombre se ha estudiado a sí mismo; ha descubierto cuales son los deberes y derechos que tiene en la sociedad; y en un esfuerzo supremo de su inteligencia, en álas [sic] de las ideas ontológicas se ha elevado á la concepción de un Dios creador de cuanto existe, y á quien tributa los homenajes de admiración y gratitud, como Autor de tan asombrosas maravillas. (Gorriti, I877, I0).

El editorial está planteado como un intento de síntesis de la evolución del pensamiento humano, de sus errores y de sus aciertos. Si bien es una mirada positivista - dado el valor que le asigna a las ciencias -, hay un marcado

del progreso del hombre era posible gracias al trabajo de la razón en busca de un conocimiento objetivo. (Barbier y Lavenir, I996, 23-24).

I9 El pozo del Yocci. París: n.p., I869; también edición prologada por Arturo Giménez Pastor. Buenos Aires, Universidad de Buenos Aires, Instituto de Literatura Argentina, Sección de documentos, Serie 4, Novela, vol. I, 5, I929. 
humanismo en el reconocimiento de que el accionar del hombre en sociedad debe estar basado en el respeto por los derechos y en el conocimiento de los deberes. A pesar de que escribe en una época desacralizada, otorga un lugar a lo sagrado.

La siguiente nota editorial, publicada el primer domingo de diciembre de I877, en el $\mathrm{n}^{\mathrm{o}}$ 3, incursiona en el tema de la "genialidad", "del hombre de genio”, y está en íntima conexión con el artículo divulgado anteriormente.

En este texto, cuyo título está planteado como una interrogación retórica, ‘Qué es el genio?’, reflexiona sobre los hombres que han enriquecido el saber humano debido a la labor por ellos realizada. El espectro abarcado es muy amplio; como científicos menciona a Galileo y a Franklin; como filósofos a Sócrates, Rousseau, Bentham y San Agustín; dentro de la literatura parte de Cervantes y luego de nombrar a otros dos españoles, Lope de Vega y Espronceda, destaca al francés Lamartine y al inglés Lord Byron. Este recorrido no respeta un orden cronológico, cita a Homero e implícitamente a Virgilio; recuerda a famosos oradores como Cicerón, Demóstenes o Mirabeau. Dentro de las personalidades artísticas distingue a dos compositores, Bellini y Rossini, y nuevamente a un escritor, Goethe. No podían quedar fuera otras formas de expresión artística como la escultura y la pintura, de allí las menciones a Miguel Ángel o a Murillo. En último término cita a quienes demostraron ser hombres de genio por medio de su actuación como estrategas y políticos: César y Napoleón.

Todas las referencias culturales presentadas a lo largo de la nota suponen un lector modelo socialmente definido que posee una vasta enciclopedia - conoce a los autores literarios y sus obras, está al tanto del mundo de la música, de la ópera, no sólo en Buenos Aires sino en Europa -, que se mueve en un entorno social en el cual se establecen redes de amistades que contribuyen a la difusión del periódico. 
El siguiente artículo editorial “Algo sobre la muger”, del 9 de diciembre, muestra en su título una vacilación ortográfica propia del siglo XIX: esta "muger" que aún pareciera no decidirse por la "j” en la pluma de la escritora, nos sugiere, a través de esa consonante, ideas como 'género, generación, grandeza, garbo, gracia...'

Esos conceptos seguramente formarían parte de su pensamiento, pues la prédica que efectuó tanto en su obra narrativa como en sus contribuciones periodísticas, estaba orientada a reafirmar la posesión de un espacio - la escritura - sin que importaran el género o las diferencias generacionales que pudieran mediar entre los autores. También sabía que la pluma de una mujer no sólo servía para contar con gracia historias del corazón sino que podía, con grande$z a$, referirse a los acontecimientos que dieron origen a un país, a sus luchas y desencuentros, así como trazar las semblanzas de los hombres que la habían conducido hasta transformarla en una realidad concreta.

Si bien comienza definiendo a la mujer a partir de sus atributos exteriores con el uso de un superlativo: el ser "mas bello de la creación”, la convierte inmediatamente en centro y responsable del bienestar y del progreso, no sólo del hombre al que acompaña, sino del de su familia y la sociedad toda. Juana Manuela tenía una certeza plena: para que esa onda se dispersase por el entramado social era fundamental que la mujer tuviera acceso a la educación (Auza, I988, 35, 37). La misma debería contemplar dos cuestiones insoslayables: por un lado, todo lo concerniente al plano intelectual; y por otro - no por ello menos importante -, lo referido a la moral y buenas costumbres, imprescindibles para desempeñar uno de los roles que prioritariamente la sociedad le asignaba: ser la portadora y transmisora de los valores y de las virtudes que formarían a las próximas generaciones. Esta afirmación es confirmada por su aseveración de que la filosofía cristiana así lo había reconocido. De alguna manera, su discurso también está dirigido al público masculino que leía la publicación, pues 
dice que todo hombre "de corazón medianamente culto" va a reconocerlo y aceptarlo; doble destinatario para un mensaje que enaltece el lugar de la mujer en la sociedad de esa época.

Como una constante en el esquema textual, establece comparaciones con la antigüedad y no duda en afirmar que toda sociedad que redujo a las mujeres a la servidumbre y a la esclavitud comenzó en ese momento su decadencia. Lo ejemplifica mediante las que llama "primeras naciones de la humanidad", las que poseían una organización basada en leyes, y donde el poder era ejercido por un rey o un faraón; pero recalca que en civilizaciones como la india, la egipcia, la hebrea o la griega, hubo un destino común para las mujeres: la esclavitud doméstica o la prostitución.

Gorriti cree que es fundamental la influencia de la mujer en la sociedad y lo demuestra por medio de la triple adjetivación que emplea para caracterizarla: “poderosa, imprescindible y fecunda”, pero advierte que al no permitírsele a la 'mujer-madre' ocupar el lugar que le corresponde, su ascendiente se vuelve un elemento negativo que afectará al núcleo familiar y conllevará a la decadencia de esa sociedad. Observa que con la llegada del cristianismo la mujer ocupa una nueva posición y es redimida del lugar de esclavitud para ser "dignificada, ensalzada, divinizada".

A partir de estos conceptos piensa un mundo perfecto donde la sociedad deje de discriminar a la mujer y de allí en adelante la considere no sólo como eje del progreso científico sino como quien logrará la paz y la armonía entre todos los pueblos.

Esta idealización abona el campo que le permite volver a una idea ya expresada: la necesidad de que la mujer acceda a la educación. Para la sociedad argentina y sudamericana de ese momento era difícil imaginarla en un papel directivo u ocupando un lugar en la política. Solo podía manifestar sus saberes e ideología a través de terceros, su esposo, sus hijos u otros familiares. 
La voz de la enunciación sostiene que la mujer educada hará más virtuosa, feliz y culta a la sociedad:

Ella es un elemento radical del verdadero progreso; y este es mas [sic] sólido, positivo y permanente cuanto mas [sic] se eduque é ilustre las condiciones intelectuales y morales de la mujer [sic], á [sic] fin de que pueda desempeñar en la sociedad su parte de labor fundamental, en la grande obra del progreso humano (Gorriti, I877, 25).

Al analizar la nota editorial aparecida en el $n^{\circ} 5$, "Fe en el porvenir" del i6 de diciembre, se comprueba que si bien es de menor extensión que las anteriores, vuelve a retomar el tema del progreso del género humano basado en la eficiencia, la razón y la fe en el futuro. No obstante, reflexiona sobre la fortaleza que la fe brinda, imprescindible para enfrentar los problemas más difíciles que, de no ser resueltos, podrían haber terminado en la "destrucción universal". Gracias a este fortalecimiento, la humanidad pudo seguir avanzando en su camino y alcanzar, por la razón y la libertad, el conocimiento de la ciencia.

Luego de realizar una generalización, confirma que fueron los intelectuales quienes introdujeron en la sociedad los ideales de la Ilustración y transmitieron al pueblo sus mismas ansias de progreso. Reconoce que la herramienta fundamental para llevar a cabo ese proyecto fue la educación, la que debía llegar hasta las clases menos favorecidas socialmente; lo que coadyuvaría de esa manera a romper con viejos esquemas, y dar paso a nuevos ideales que auguraban una vida más feliz y más justa para todos.

Interesa destacar que antes de la nota editorial publicada el domingo 23 de diciembre, correspondiente al $n^{\circ} 6$, la dirección del Semanario transcribe la carta que había cursado a prestigiosas personalidades del quehacer cultural para que actuaran como jurados en la selección del material que luego sería publicado en La Alborada. Entre ellos figuraban el joven escritor Santiago Estrada, 
el Dr. Santiago V. Guzmán, Don Mariano A. Pelliza y Don Eduardo Bustillo. Es evidente que Juana Manuela Gorriti es la autora de esa circular; así lo prueba el empleo de los deíticos posesivos de primera persona: “mi deber..., me es necesario..., mi suficiencia...", así como por la firma de la misma: "La Directora”. De esta manera busca, por un lado, prestigiar la publicación al contar con un jurado que se expida sobre el valor de las producciones y, por otro, no sentir la agobiadora responsabilidad de que la selección del material editado recaiga sólo sobre sí. Una vez más queda demostrado lo moderno de su pensamiento, pues está solicitando el referato para prestigiar su periódico.

El editorial "Americanismo", por sus características, permite establecer algunas diferencias con el resto de las notas analizadas: en primer término, su extensión; en segundo lugar, su temática, y por último, ciertos cambios de estilo.

En cuanto al primer punto es el editorial más extenso escrito hasta ese momento.

Con respecto a la temática, pareciera reelaborar algunos de los conceptos propuestos en el 'Prospecto': en aquel momento había hecho hincapié en la necesidad de dar a conocer la literatura americana; ahora desarrolla más detenidamente la cuestión pues propone alentar la producción de una literatura nacional, que deberá rescatar elementos característicos de cada nación como el paisaje, la flora o la fauna. Para lograrlo juzga fundamental enriquecer las obras con la inclusión de las voces americanas que designan los elementos descritos, acrecentando de esta manera el potencial idiomático (Masiello, I997, 64). Juana Manuela era partidaria de este bilingüismo; así lo demuestra la decisión de publicar la poesía "Manchaypuito o el Yaraví de la la quena”, en la que transcribe primero la versión en quechua y luego la presenta en castellano, con una nota al pie donde aclara que ha suprimido aquellos versos que pudieran ofender el honor de las lectoras. 
Al instalar el tema de la defensa del patrimonio cultural americano, la editora muestra la firmeza de sus ideas en cuanto a la necesidad de preservarlo y fomentarlo, a la vez que plantea una muy dura crítica a los literatos europeos pues opina que en sus escritos falsean datos sobre los usos, las ceremonias o la historia y geografía propias de América.

Al igual que en el "Prospecto", revaloriza nuevamente a la novela como el género más adecuado para llegar a los miles de destinatarios que podían tener los periódicos americanos, pero rescata otro tipo de producción literaria que comenzó a brillar a principios del siglo XIX en Francia: el folletín. Es consciente de la popularidad del mismo y de la capacidad que tenía para transmitir historias y despertar el interés de un público que se transformaba en cautivo al seguir semanalmente las peripecias por las que transcurría la vida de los personajes. Agudamente observa que muchos autores europeos habían trascendido y alcanzado fama a través de esa forma de publicación secuenciada de sus obras en los periódicos más importantes del momento, como Víctor Hugo, Alejandro Dumas, Honoré de Balzac, Maurice Leblanc y George Clavigny, entre otros. Deduce que lo mismo sucederá con los hombres de genio argentinos que de esta manera serían conocidos por los lectores americanos, por lo que propone se contemple la posibilidad de inclusión de sus producciones en forma de novela de folletín.

Hay que recordar que los diarios de Buenos $\operatorname{Aires}^{2 \circ}$ ya realizaban la publicación de novelas europeas y argentinas con esa modalidad, tal como sucedía en La Tribuna, donde aparecieron así publicadas dos novelas de Eduarda Mansilla $^{21}$ en i860. Otro tanto ocurrió con la obra que Juan María Gutiérrez había

20 Después del año I850 existieron importantes periódicos como: La Prensa, La Nación, El Progreso, El Paraná, La Tribuna, La Crónica, La Reforma, El Siglo, La República, El Pensamiento o El Río de la Plata. 2I Eduarda Mansilla de García, (1838-I892), escribió ese año El médico de San Luis y Lucía Miranda. 
escrito en I843, El capitán de Patricios, que fue presentada como folletín en El Correo del Domingo de Buenos Aires, en abril de i864. Un caso interesante es el de Bartolomé Mitre, quien exiliado en Bolivia, dirigía en el año I847 el diario La Época de la ciudad de La Paz. Allí publicó por entregas su novela Soledad y ese mismo año también dio a conocer en un periódico quincenal de Valparaíso, su obra La Mariposa. Vicente Fidel López, quien encarna el romanticismo histórico en el Río de la Plata, publicó su novela La novia del hereje, por entregas, en El Plata Científico y Literario en I851.

La editora aspira a que esta idea sea bien recibida por otros escritores ya que conoce por propia experiencia la realidad de países americanos como Perú, Chile, Bolivia y Colombia. En suma, es una manera de reforzar su pensamiento sobre la necesidad de un panamericanismo que se vería fortalecido a través de producciones literarias de distinto origen.

Eso le permite reflexionar, como ya había hecho en otros artículos, sobre la posibilidad de que la mujer tenga acceso a una literatura nacional que refleje las "costumbres haciendo amar la sencillez republicana y los goces tranquilos del hogar". Piensa que es en esas lecturas donde hallará el modelo para realizar su "verdadera misión". Si nos detenemos en el análisis de estas pocas palabras podremos percibir que surgen algunos conceptos que Juana Manuela tuvo como eje de sus producciones al plantearse cuál era la función de la literatura y su influencia en la sensibilidad femenina. Tiene el firme convencimiento de que la literatura es dadora de identidad, defensora de las ideas democráticas de gobierno, transmisora de valores, la que podrá ser comprendida y aprehendida sólo por una mujer capacitada, cuyo rol trascienda el plano del hogar, - lugar donde desarrollará su primera misión como madre y educadora -, para poder luego integrarse y formar parte activa de una sociedad que necesitará de ella en la conformación de la Nación. 
En la publicación del último domingo de ese año, $\mathrm{n}^{\circ} 7$ del 30 de diciembre, aborda más frontalmente la cuestión política. Titula el editorial "La democracia" - y a modo de continuación -, "Y el sistema federativo". Para desarrollarlo, retoma el esquema argumentativo presentado en notas anteriores. Primero, plantea una breve definición del tema que va a tratar; a continuación, establece una comparación con los pueblos de la antigüedad, especialmente los que cimentarán la cultura occidental; luego lo relaciona con los tiempos modernos y cierra el texto con una conclusión.

Al establecer la comparación con el mundo griego, destaca los principios en él alcanzados: la libertad, la justicia, la democracia, pero razona que los derechos de sus habitantes no fueron realmente respetados, debido a que estos eran en su mayoría esclavos. La radical diferencia con las democracias modernas reside, según la opinión de la editora, en que dentro de ellas los hombres son considerados "ciudadanos" y se les reconocen derechos como la igualdad, la libertad e inviolabilidad de pensamiento y de conciencia. Alaba el sistema federal de gobierno como vehículo de vida, desarrollo y crecimiento para todo el país: "El sistema federativo viene a llenar un vacío, á [sic] cumplir una necesidad; en los paises centralizados languidece el cuerpo nacional en beneficio de la capital..." (Gorriti, I877, 50). Juzga que la adopción de este sistema enaltece a aquellos países que lo poseen, de allí que "la República Argentina en América”, se halle a la altura de países como "Estados Unidos del Norte” y la "Suiza de Europa”.

El primer número del año I 878 , publicado el 6 de enero, continúa con la numeración correlativa, ya que se imprime con el $n^{\circ} 8$. Se transcriben las cartas de aceptación que cursaron los Sres. Bustillo, Guzmán y Pelliza para conformar el jurado de revisión de los trabajos recibidos y determinar cuáles se publicarían. Sólo se excusa su gran amigo Santiago Estrada, por impedírselo sus ocupaciones. De esta manera la Directora cuenta con el apoyo de destacados intelectuales que cuidarán la calidad del material impreso. Es posible que ya estuviera en 
la mente de Juana Manuela la idea de viajar al norte, de regresar al paisaje, el perfume y los colores de su tierra natal; ya podía emprender ese proyecto tranquila y aliviada de la inmensa responsabilidad que le generaba la publicación, semana tras semana, de La Alborada. El espacio ya había sido creado; otros deberían proseguir la tarea periodística por ella emprendida.

La que sería la última nota editorial bajo la dirección de la escritora, "División de la enseñanza y el trabajo", desarrolla un tema reiterado a lo largo de los discursos analizados, el de la educación, pero avanza un poco más en sus consideraciones sobre quiénes debían ser responsables de impartirla.

En la primera parte reflexiona sobre los males que acarrea para una nación el hecho de que el conocimiento científico permanezca en manos de unos po$\cos$, lo que origina una separación de clases en la que una gran mayoría queda sumida en la ignorancia.

Para examinar esta idea realiza un recorrido por el camino que emprendió la humanidad en la adquisición de las ciencias. Retoma un concepto desarrollado en la nota editorial del $n^{\circ}$ 2, es decir, establece cuáles deben ser los objetivos de la ciencia: descubrir la verdad por medio de principios ciertos y evidentes. Una vez que se ha logrado ese cometido es fundamental la enseñanza de tales verdades, las que deben ser obligatoriamente brindadas por las autoridades de la nación. Reafirma el derecho constitucional que poseen todos los habitantes a educar y ser educados, y establece claramente que una de las funciones democráticas que debe llevar adelante todo gobierno es la de garantizar el derecho a la educación.

Expone luego la idea que da título al artículo: la necesidad de implementar en el ámbito de la enseñanza la teoría económica de la división del trabajo. Según el criterio de la editora, la educación en las sociedades modernas puede estar dividida en cuatro grandes áreas: "La instrucción religiosa, científica, literaria y política". Las responsables de brindar los conocimientos referidos 
a estas temáticas serían aquellas partes constitutivas de la sociedad que más conocimientos tuvieran sobre las mismas. Propone que las instituciones confesionales se ocupen de la instrucción religiosa, y para las restantes disciplinas recomienda se creen "universidades de ciencias, letras, política y administración", un pensamiento de avanzada para estas latitudes.

Concluye la nota con una fuerte adhesión a las propuestas educativas que fueron establecidas por Domingo F. Sarmiento en cuanto a la obligatoriedad del Estado de impartir instrucción primaria a todas las clases sociales. Afirma que la nación es la que debe proporcionar enseñanza, convirtiéndose así en centro civilizador y de cultura. Por último, retoma la idea que motiva el artículo y expresa que "sin la división del trabajo, debidamente aplicada a la enseñanza, no saldremos de la antigua senda..." (Gorriti, I878, 59). Por tanto, estima que es imperativo aplicar este principio para ingresar en el camino que haga de la Argentina una nación moderna.

Por último, la publicación del i3 de enero de i 878 comienza con la carta que Juana Manuela dirige a todos sus lectores, en la que aclara el porqué de su alejamiento de la conducción del Semanario y su decisión de dejar la dirección de La Alborada en manos de Josefina Pelliza de Sagasta. De esa manera, el legado recae en otras manos de mujer y se constituye en un rasgo de reconocimiento y en una distinción de la escritora experimentada hacia la nueva generación que transitaba el duro camino de consolidar un ámbito para la mujer escritora argentina.

El $n^{\circ} 9$ cierra el ciclo de Juana Manuela como editora responsable, aunque tanto en este número como en los subsiguientes continuará participando activamente en La Alborada a través de diferentes colaboraciones. 'El mosaico" de este número le pertenece, como el de todos los números anteriores, e incluye en él un relato fantástico titulado "Espiritismo" que luego será recogido dentro de Misceláneas (I878), en Escenas de Buenos Aires² (Molina, I999b, II-45).

22 Publicadas en Obras Completas, tomo II. 
Pero a pesar de que se produce este desprendimiento como directora, no deja de participar - como tantas otras escritoras y escritores -, en las publicaciones periódicas no sólo del país sino de América.

\section{CONCLUSIONES}

La solvencia que mostró Juana Manuela Gorriti en la elaboración de sus escritos, tanto de ficción como periodísticos, en la tarea educativa o como anfitriona de las veladas literarias, pone de relieve su amplia cultura, poco frecuente en una mujer del siglo XIX, producto de las lecturas que, en la biblioteca paterna desde pequeña la habían nutrido, así como de las observaciones que con espíritu atento y agudo realizó de la realidad histórica y cultural del tiempo en que vivió.

Toda su obra demuestra que el espacio femenino no debía ceñirse sólo al ámbito doméstico. Creía y reafirmaba a través de su propio ejemplo de vida que la mujer estaba llamada a desempeñar más de un papel: el de madre, - guardiana de las virtudes del hogar -; el de educadora; el de difusora de cultura y valores; el de ciudadana; pero todos estos roles debían jugarse sin perder de vista que eran partes constitutivas de un único ser. Es decir, que el cumplimiento del primero no invalidaba que se destacara en otros ámbitos, tanto los referidos a la política y a la vida en democracia como los que le demandaba su vida social (Sledziewski, 2000, 53-70). Pero para que la mujer pudiera llevar adelante dignamente todas estas funciones era imprescindible que lograra acceder a la educación.

Esto nos lleva a plantear binomios que seguramente formaban parte del ideario de Juana Manuela: mujer-madre; mujer-lectora; mujer-educadora; mujer-pensadora política; o la ecuación: mujer - hogar - sociedad - patria.

La mujer está siempre presente en su producción: es la heroína que sufre en las contiendas civiles, que padece las crisis sociales, que ama u odia al enemigo 
de bandería política opuesta en la guerra. Es vencedora o es vencida. Es ama o esclava. Es amada u olvidada.

Sus textos editoriales proponen una innovación, ya que defienden la tesis ilustrada y bregan por el acceso de la mujer al campo cultural que le estaba vedado; rasgos todos que inscriben en la modernidad sus producciones, pero no debe pensarse por ello en una actitud complaciente, sino que, por el contrario, actuó con total libertad para expresar sus opiniones.

Esta misma realidad es la que vivían las escritoras de fines del siglo XIX, quienes debían luchar por encontrar un lugar propio en los círculos literarios masculinos. Es por ello que sin rendirse ante las dificultades, mantuvieron salones literarios, fundaron periódicos, publicaron libros y artículos periodísticos, en los que los temas de la mujer, la educación, la sociedad, la política, fueron tratados desde una óptica diferente.

Mujeres como Juana Manuela Gorriti, Eduarda Mansilla, Juana Manso, Mercedes Cabello, Clorinda Matto, Carolina Freyre, Lola Larrosa, Josefina Pelliza, unidas por similares ideales e incluso por la amistad, gestaron una generación periodística y literaria más que argentina, latinoamericana.

En ese contexto, con el fuerte espíritu combativo por el que fue conocida en su vida privada y pública, Juana Manuela Gorriti encaró, con reconocimiento y éxito, la difícil y controversial tarea del periodismo y marcó un rumbo para las futuras escritoras del siglo XX. 
JUANA MANUELA GORRITI, UNA PERIODISTA ARGENTINA DEL SIGLO XIX

MARINA LILIANA GUIDOTTI

referencias bibliográficas

Auza, Néstor, Periodismo y feminismo en la Argentina. Buenos Aires: Emecé, I9 $88,28-59$.

Batticuore, Graciela, El taller de la escritora. Veladas literarias de Juana Manuela Gorriti: Lima-Buenos Aires (1876/7-1892). Rosario: Beatriz Viterbo, I999, 39-50.

Batticuore, Graciela, La mujer romántica. Lectoras, autoras y escritores en la Argentina: 1830-1870. Buenos Aires: Edhasa, 2005, 275-327.

Barbier, Frederic y Catherine Bertho Lavenir, Historia de los medios de Diderot a Internet. Buenos Aires: Colihue, I996, 23-24.

Berg, Mary, "Mujeres y exiliadas en la narrativa de Juana Manuela Gorriti”. Fletcher, Lea (comp.), Mujeres y cultura en la Argentina del siglo XIX. Buenos Aires: Feminaria, I994, 69-79.

Berg, Mary, Las desobedientes: Mujeres de nuestra América, Betty Osorio y María Mercedes Jaramillo (eds.). Bogotá: Panamericana Editorial, I997, I3I-I46.

Catelli, Nora, Testimonios tangibles. Pasión y extinción de la lectura en la narrativa moderna. Barcelona: Anagrama, 200I, 2I-25.

Deleis, Mónica, Ricardo de Titto, Diego Arguindeguy, Mujeres de la política argentina. Buenos Aires: Aguilar, 200I, pp. I4I-I55.

Efrón, Analía, Juana Gorriti, Una biografía íntima. Buenos Aires: Sudamericana, 1998.

Gorriti, Juana Manuela, La Alborada del Plata. Buenos Aires: Imprenta Biedma, I877.

Gorriti, Juana Manuela, Obras completas. Salta: Fundación Banco del Noroeste, Ed.Noa, I993, VI tomos.

Lojo, María Rosa, "Nuestras primeras escritoras". Fundación. Política y Letras, Año V, N I2, Diciembre I997, I92-I97. 
Masiello, Francine, Entre civilización y barbarie. Mujeres, Nación y Cultura literaria en la Argentina moderna. Buenos Aires: Beatriz Viterbo Editora, I997, 62-68.

Masiello, Francine, La mujer y el espacio público. El periodismo femenino en la Argentina del siglo XIX. Buenos Aires: Feminaria, (I994): 7- I9.

Molina, Hebe, La narrativa dialógica de Jana Manuela Gorriti, Mendoza: Editorial de la Facultad de Filosofía y Letras, ı999a, 54-72.

Molina, Hebe, "La Alborada del Plata. Literatura. Artes. Ciencias. Teatro y Modas” . Historia de las Revistas Argentinas, Tomo III. Buenos Aires: Asociación Argentina de Editores de Revistas, I999b, II-45.

Sledziewski, Elisabeth, “Revolución francesa. El giro”. Fraisse, Geneviève y Michelle Perrot, Historia de las mujeres en Occidente. Tomo 4, el siglo XIX. Madrid: Taurus, 2000, 53-70.

Sosa de Newton, Lily, Diccionario Biográfico de Mujeres Argentinas. Buenos Aires: Plus Ultra, I986, 286-287. 